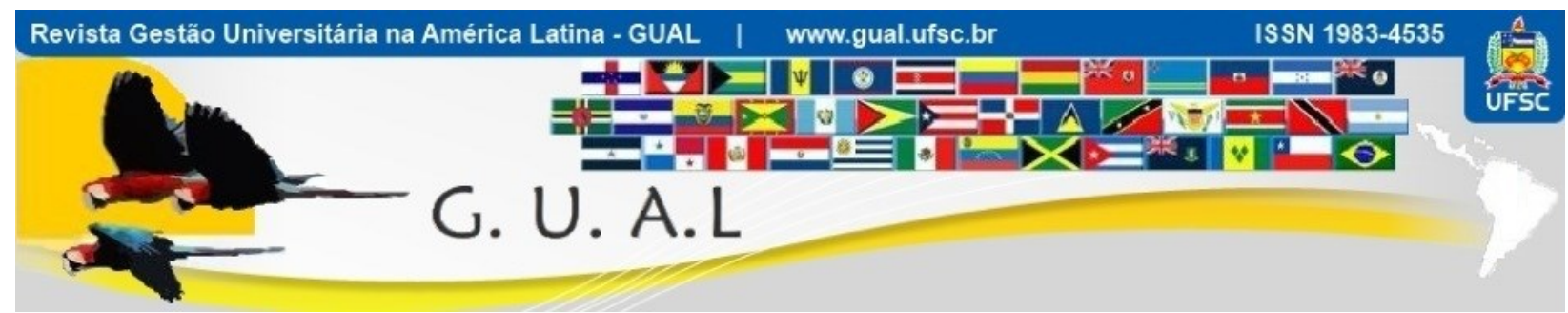

DOI: http://dx.doi.org/10.5007/1983-4535.2016v9n3p174

\title{
SENTIDO DO TRABALHO: UMA ANÁLISE SOBRE A PERCEPÇÃO DOS COORDENADORES DE CURSOS EM UMA INSTITUIÇÃO UNIVERSITÁRIA
}

\author{
SENSE OF WORK: AN ANALYSIS ON THE PERCEPTION OF COURSE \\ COORDINATORS IN AN UNIVERSITY INSTITUTION
}

Carlos César Ronchi, Mestre

Universidade Ceuma ccronchi@ibest.com.br

Nehemias Pinto Bandeira, Mestre Universidade Ceuma nehemiasbandeira@hotmail.com

Carlos Henrique Mendes Braga, Graduado Universidade Ceuma c hmb@hotmail.com

Ricardo Daher Oliveira, Doutor Universidade Ceuma ricardo.daher@hotmail.com

José Samuel de Miranda Melo Jr, Doutor Universidade Ceuma e Universidade Estadual do Maranhão - UEMA admsamueljr@gmail.com

Recebido em 27/julho/2014

Aprovado em 29/agosto/2016

Sistema de Avaliação: Double Blind Review

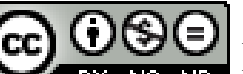

Esta obra está sob uma Licença Creative Commons Atribuição-Uso. 


\title{
RESUMO
}

O presente artigo é resultado de uma pesquisa que buscou compreender o trabalho e seu sentido, tendo em vista os aspectos que influenciam o ambiente organizacional. O objetivo desta pesquisa é diagnosticar o que os coordenadores de curso de uma universidade maranhense, atribuem ao sentido do trabalho. Para que fosse possível o alcance dos resultados, foi utilizado um questionário, que envolve dimensões relacionadas ao sentido do trabalho e questões socioeconômicas. Os resultados expressam que os coordenadores de curso atribuem uma concepção positiva quanto ao trabalho, sociedade e às organizações. Ao analisar os dados, percebe-se que os pesquisados não consideram o dinheiro um fator essencial para realizarem suas atividades, e que o trabalho oferece uma contribuição para a sociedade, assim beneficiando os outros e permitindo o aperfeiçoamento. Constata-se que o trabalho na percepção dos pesquisados, é considerado mentalmente exigente. Ao analisar a pesquisa, destaca-se que os investigados consideram o sentido do trabalho como algo fundamental e agregador de valor, pois contribui para o crescimento pessoal e coletivo, tornando-se significante em suas vidas.

Palavras-chave: Trabalho. Sentido do trabalho. Sociedade. Organizações.

\begin{abstract}
This article is resulting from a research that sought to understand the work and its sense, bearing in mind the aspects that influence the organizational environment. This research aims to diagnose what the course coordinators from a Maranhense university attribute to the sense of work. To make it possible to achieve results, a questionnaire has been used, which involves dimensions related to the sense of work and socioeconomic questions. The results express that the course coordinators attribute a positive conception regarding to the work, society and the organizations. When analyzing data, it is noted that the person researched does not consider money as an essential factor to perform its activity, and that the work offers contribution to the society, thus benefiting others and allowing improvement. One can see that the work in the perception of the person researched, is considered mentally demanding. When analyzing the research, it is highlighted that the people investigated consider the sense of work as something fundamental and aggregator of value, because it contributes to the personal and collective growth, becoming it significant in their lives.
\end{abstract}

Keywords: Work. Sense of work. Society. University. Management. 


\section{INTRODUÇÃO}

A temática deste artigo está relacionada ao sentido do trabalho na percepção dos coordenadores de curso de uma universidade maranhense, assim desenvolvendo importantes direcionamentos para o entendimento do tema nesse setor. A principal proposta é entender a percepção acerca do sentido do trabalho para esses profissionais, mesmo diante de inúmeras demandas que o cargo exige, pois as evidências indicam uma forte influência no cotidiano organizacional sobre as ações e sentimentos desses indivíduos. Pode-se inferir que o trabalho possa ser visto além de uma atividade que gere remuneração, a autorrealização e outros aspectos desenvolvidos por cada profissional são fundamentais para o significado do trabalho. O trabalho que faz sentido depende principalmente do indivíduo que o realiza, pois os resultados obtidos por ele se refletirão diretamente para a sociedade.

O objetivo principal do presente artigo é diagnosticar o que os coordenadores de curso atribuem ao sentido do trabalho, debatendo evidências que influenciam o trabalho e seu desempenho, na percepção dos pesquisados. Nesse contexto, a reflexão sobre implicações organizacionais nesse constructo, está relacionada a respeito do que é realizado para dar sentido ao trabalho dos coordenadores. A dedicação e a força de vontade são fatores que influenciam de maneira significativa os resultados do trabalho. Considerando-se a relevância do tema abordado por esta pesquisa, o presente artigo tem como problema o seguinte questionamento: De que modo as características atribuídas ao trabalho dos coordenadores de curso de uma universidade podem influenciar o sentido do trabalho?

\section{SOCIEDADE E MUNDO CONTEMPORÂNEO LÍQUIDO}

As evidências indicam que, no mundo líquido, os sujeitos estão perdendo a sua liberdade. Desta maneira, Bauman (2001, p. 28) afirma que "não só não há contradição entre dependência e libertação: não há outro caminho para buscar a libertação senão "submeter-se à sociedade" e seguir as normas. A liberdade não pode ser ganha contra a sociedade." O trabalho é central a vida das pessoas, e ao mesmo tempo importante para quem busca ter algum sentido. Nessa conjuntura, Tolfo e Piccinini (2007, p. 39) expressam que "centralidade do trabalho é entendida como o grau de importância que o trabalho tem na vida de uma pessoa em um determinado momento." As organizações começam a tomar centralidade da vida das pessoas, e a impor suas práticas. Sob esse fundamento, Gaulejac (2007, p. 275) relaciona que “em toda organização, os indivíduos adaptam seu comportamento aos parâmetros segundo os 
quais pensam ser julgados." A centralidade do trabalho é característica da sociedade contemporânea, e torna-se importante a sua compreensão. Nessa perspectiva, Andrade, Tolfo e Dellagnelo (2012, p. 205) afirmam que "a centralidade do trabalho consiste no grau de importância atribuída a ele em comparação com as demais esferas da vida.”

$\mathrm{Na}$ sociedade, o resultado do trabalho se refletirá diretamente para que a sua identidade seja compreendida, mesmo diante de tamanha complexidade. Nesse contexto, Freitas (2000, p. 7) exprime que "tudo o que existe numa sociedade é produção dessa sociedade e somente assim pode ser ela compreendida." Em uma sociedade globalizada e cheia de informação, de fato ainda existe a individualização do homem em relação à convivência em grupo. Nessa dinâmica, Bauman (2001, p. 123) afirma que "a capacidade de conviver com a diferença, sem falar na capacidade de gostar dessa vida e beneficiar-se dela, não é fácil de adquirir e não se faz sozinha."

A busca de independência é classificada como uma necessidade, assim fazendo com que o indivíduo possua uma autonomia relativa. Para conquistar essa independência é preciso superar os desafios impostos pelas organizações. Nessa perspectiva, Ronchi (2010) pontua que há uma necessidade dos indivíduos de quererem ser independentes e terem o controle de sua vida, porém não há como negar que as organizações tornam isso distante para a maioria das pessoas envolvidas no processo. Sob essa dinâmica, Gaulejac (2007, p. 29) explica que "na sociedade hipermoderna cada indivíduo pode ser ao mesmo tempo produtor e produto do sistema, ser o ator agente dele, fazê-lo funcionar, tanto quanto suportá-lo." Ao se correlacionar produtor e produto do sistema, faz-se necessário pensar na flexibilidade do homem em produzir algo que tenha retorno, não só na individualidade, mas sim na coletividade.

No contexto, apesar do aumento da rentabilidade, da produtividade e de outras variáveis pertinentes, percebe-se que o sofrimento humano se acentua diante do hiperfuncionamento de organizações geridas pela excelência. Nessa perspectiva, Aubert (1993, p. 102) expressa que “o indivíduo é conduzido a desenvolver e buscar uma imagem de si mesmo em conformidade com os padrões exteriores de excelência e de sucesso, às vezes, em detrimento de sua personalidade real." Nesse contexto, Gaulejac (2007, p. 153) esclarece que "o mundo parece cada vez mais "insensato": os ganhos de produtividade não impedem as demissões, as ações sobem o descem, sem ligação clara com os desempenhos efetivos, empresas fecham apesar de serem rentáveis." A evolução do conhecimento é uma realidade. 
Sendo assim, pode-se inferir que há uma busca constante, de muitos, para a sua produção. Embora as teorias façam distinções e aproximações, características sobre o indivíduo e a sua evolução na sociedade estão expressas conforme tabela a seguir:

Tabela 1 A evolução do indivíduo na sociedade.

\begin{tabular}{c|l}
\hline Autores & \multicolumn{1}{c}{ Definições } \\
\hline Freitas & $\begin{array}{l}\text { As sociedades e os povos diferem em função do que amam, detestam, querem, desejam, } \\
\text { sonham, buscam. Uma sociedade institui-se criando para si a representação de uma visão de } \\
\text { mundo, do seu mundo e do mundo que ela conhece. }\end{array}$ \\
Bauman & $\begin{array}{l}\text { A sociedade é hoje antes de tudo a condição de que os indivíduos precisam muito, e que lhes } \\
\text { faz falta. }\end{array}$ \\
Lipovetsky & $\begin{array}{l}\text { A sociedade hipermoderna se apresenta como a sociedade em que o tempo é cada vez mais } \\
\text { vivido como preocupação maior; a sociedade em que se exerce e se generaliza uma pressão } \\
\text { temporal crescente. } \\
\text { Cada indivíduo é produtor da sociedade e das organizações nas quais ele vive. }\end{array}$ \\
Gaulejac & $\begin{array}{l}\text { A emergência das relações diversificadas de trabalho, muitas vezes pode levar o indivíduo a } \\
\text { não se identificar com as atividades, e questionar-se sobre seus significados e sentidos. }\end{array}$ \\
\hline Tolfo et al. &
\end{tabular}

Adaptado de: Bauman (2001, p. 51), Freitas (2000, p. 7), Gaulejac (2007, p. 296), Lipovetsky (2004, p. 75), Tolfo et al (2011, p. 175).

O indivíduo interage na sociedade através de suas atividades, sejam laborais sejam sociais; desta forma, o espaço social é reformulado pela evolução dos conceitos e novas articulações. Com base nesse argumento, Bauman (2001, p. 39) estatui que "a sociedade moderna existe em sua atividade incessante de "individualização," assim como as atividades dos indivíduos consistem na reformulação e renegociação diárias da rede de entrelaçamentos chamada "sociedade." Ao desenvolver esses argumentos, Bauman (2001, p. 39) explica que "o significado da "individualização" muda, assumindo sempre novas formas." O autor pontua também que "a "individualização" agora significa uma coisa muito diferente do que significava há cem anos e do que implicava nos primeiros tempos da era moderna."

O indivíduo tem a liberdade de escolher qual caminho deverá seguir, contribuindo ou não para o crescimento coletivo. A organização não tem como controlar o comprometimento e o desempenho das pessoas. Deve-se entender que a sociedade é um ambiente em que o indivíduo se desenvolve, articula-se e interage, influenciando e sendo influenciado pelo ambiente profissional. Com base nesse argumento, Bauman (2001, p. 50, grifo do autor) afirma que "Sociedade sempre manteve uma relação ambígua com a autonomia individual: era simultaneamente sua inimiga e condição sine qua non." O trabalho poderá ser realizador 
para o ator da sociedade. Nessa perspectiva, Gaulejac (2007, p. 119) enuncia que "o trabalho deve torna-se o lugar da realização de si mesmo."

\section{SENTIDO DO TRABALHO}

O Trabalho é de fundamental importância para o desenvolvimento das pessoas, e o seu sentido é a visão de como cada indivíduo tem seu desempenho. Morin (2001, p. 18) expressa que "para que um trabalho tenha sentido, é importante que quem o realize saiba para onde ele conduz." A clareza nos objetivos sobre o trabalho e a busca necessária de resultados é considerada um avanço no seu sentido. Nessa perspectiva relata que são essenciais e importantes a clareza e a valorização dos objetivos, desenvolvendo resultados que tenham valor aos olhos de quem o realizam (MORIN, 2001). Nessa perspectiva, a busca de conhecimento transforma a vida das pessoas e das organizações, assim gerando reflexos positivos para a obtenção de resultados, com o objetivo de evoluir o nível dos indivíduos e consequentemente das organizações.

A compreensão do sentido do trabalho é importante para a evolução das organizações. E quem faz o trabalho ter sentido é quem o realiza. A partir deste entendimento, Tolfo e Piccinini (2007, p. 40) conceituam que "o sentido do trabalho é compreendido como um componente da realidade social construída e reproduzida, que interage com diferentes variáveis pessoais e sociais e influencia as ações das pessoas e a natureza da sociedade num dado momento histórico." Quando se fala de produtividade, pode-se pensar que os resultados sejam satisfatórios, e quem consegue desenvolver suas habilidades, sendo útil, a sociedade reconhece e dignifica. Nessa dinâmica, Gaulejac (2007, p. 182) exprime que "a vida humana deve ser produtiva. A sociedade se torna uma vasta empresa que integra aqueles que lhe são úteis e rejeita os demais." A busca de sentido no trabalho que é realizado torna-se necessária para obter resultados satisfatórios para o indivíduo e, consequentemente, para a coletividade. É fundamental a contribuição de todos os envolvidos no processo.

O trabalho que tem sentido é realizado de maneira que possa contribuir de forma efetiva para o desenvolvimento e crescimento da sociedade. Tolfo e Piccinini (2007) ressaltam que no momento em que o trabalho não contribui, deixa de trazer benefícios para alguém e/ou para a sociedade, ele não faz sentido. O sentido do trabalho pode estar associado às organizações no que tange à melhoraria de forma produtiva, do desempenho e do potencial das empresas. Desta maneira, se as organizações dessem ênfase em ações relacionadas ao 
sentido do trabalho, tendo em vista o bem-estar e a autorrealização dos colaboradores, poderiam alcançar melhores resultados. Para que o trabalho tenha sentido e possa contribuir de forma efetiva às organizações, é importante a participação de todos os envolvidos no processo. Sob essa premissa, Morin (2001, p. 9) afirma que "a organização do trabalho deve oferecer aos trabalhadores a possibilidade de realizar algo que tenha sentido, de praticar e desenvolver suas competências, de exercer seus julgamentos e seu livre-arbítrio, de conhecer a evolução de seus desempenhos e de se ajustar." O resultado a ser almejado pelo trabalho visa não só o próprio indivíduo, mas também a coletividade envolvida no processo. Sob esse fundamento, Gaulejac (2007) conceitua que o trabalho tem sentido visto que dá o sentimento de contribuir para uma obra coletiva e que cada atividade tem um fim fora de si mesmo.

\section{TRABALHO: SIGNIFICADO E CONSEQUENNCIAS (PRAZER E SOFRIMENTO)}

As pessoas, ao longo de suas vidas, buscam adaptar-se às mudanças, tendo como objetivo maior a possibilidade de crescimento. O trabalho está além do tempo que é exercido uma determinada atividade, ele contribui e modifica a personalidade e as características que o sujeito possui. Nessa composição, Dejours (2004, p. 31) exprime que "o trabalho não é, como se acredita frequentemente, limitado ao tempo físico efetivamente passado na oficina ou no escritório. O trabalho ultrapassa qualquer limite dispensado ao tempo de trabalho; ele mobiliza a personalidade por completo.” Praticar um trabalho que possa ser utilizado como referência, buscando estabelecer uma conexão com o seu desempenho e a produtividade, poderá trazer inúmeros benefícios para a organização e ao próprio sujeito. Corroborando esse argumento, Enriquez (2000) expressa que os trabalhadores investem em seu trabalho, dele se apropriam, dão-lhe um sentido e inscrevem uma parte de seus desejos e de seus projetos na organização.

O trabalho apresenta-se como um norteador para eventuais mudanças ocorridas na vida das pessoas. A realização de um trabalho, que tenha sentido, dependerá de todas as partes envolvidas, possibilitando a realização das tarefas atribuídas. A partir desse entendimento, Morin (2001, p. 9) enfatiza que "o trabalho conserva um lugar importante na sociedade. Os esforços para reorientar os comportamentos fora dos padrões e para reforçar os comportamentos produtivos ainda não são suficientes para solucionar os problemas de produtividade enfrentados pelas empresas.” 


\section{SENTIDO DO TRABALHO: UMA ANÁLISE SOBRE A PERCEPÇÃO DOS COORDENADORES DE CURSOS EM UMA INSTITUIÇÃO UNIVERSITÁRIA \\ DOI: http://dx.doi.org/10.5007/1983-4535.2016v9n3p174}

A participação do indivíduo de maneira assídua no processo é fundamental para o aumento da produtividade. Sobre essa premissa, Gaulejac (2007, p. 82) explica que "o indivíduo submetido á gestão deve adaptar-se ao "tempo do trabalho", às necessidades produtivas e financeiras. A adaptabilidade e a flexibilidade são exigidas em mão única.” As organizações são constituídas por valores e crenças, nos quais poderão influenciar o indivíduo ao desenvolver seu trabalho. Tamayo (2005) afirma que os valores organizacionais constituem formas culturais socialmente aceitas para expressar as necessidades e interesses da organização enquanto grupo e enquanto instituição de negócios. Na organização do trabalho, por ser um sistema formalizado da sociedade, faz-se necessário desenvolver suas características para melhor entender suas transformações. Nesse cenário, Motta (1993, p. 69) conceitua que "a organização é o sistema social mais formalizado da sociedade, sendo, portanto, um sistema de significativas condutas institucionalizadas."

A participação das organizações no desenvolvimento dos indivíduos é uma iniciativa que necessita ser enriquecida e aprimorada, de maneira que o trabalho e seu sentido tenha cada vez mais valor. A meritocracia e outros elementos fundamentais como o conhecimento, valores, inovação, tecnologia, processos, tornam-se essenciais para evolução do sujeito na organização. Nesta linha de raciocínio, Gaulejac (2007, p. 220) explica que "não é a organização que, definitivamente, se torna responsável pelo lugar atribuído a cada um, mas o "mérito" de cada um, que é considerado como determinante do lugar ocupado."

Com o trabalho transformando-se a cada dia, cumpre, então, entender-lhe a evolução de tal maneira que possa contribuir o seu progresso e significado. Nessa perspectiva, Ronchi (2010) ressalta que o trabalho pode ser considerado como um dos meios fundamentais que declaram o indivíduo à sua natureza humano-social. Através das suas experiências, valores, crenças e pressupostos, cada indivíduo vai criando o significado particular do trabalho.

O trabalho é um conjunto de esforços praticado pelo sujeito com o objetivo de aprimorar seu potencial e formar uma identidade acerca do sentido e significado que o trabalho traz para si e para a sociedade. Gaulejac (2007) fundamenta o argumento de que o trabalho se tornou o elemento essencial para fixar a posição de cada um na sociedade e para canalizar as finalidades da existência sobre a carreira profissional. Mesmo com tantas transformações, que ocorrem ao longo do tempo, a construção da identidade do indivíduo permanece em constante adaptação. Nessa dinâmica, Hall (2009, p. 108) exprime que "as identidades estão sujeitas a uma historicização radical, estando constantemente em processo 


\section{SENTIDO DO TRABALHO: UMA ANÁLISE SOBRE A PERCEPÇÃO DOS COORDENADORES DE CURSOS EM UMA INSTITUIÇÃO UNIVERSITÁRIA \\ DOI: http://dx.doi.org/10.5007/1983-4535.2016v9n3p174}

de mudança e transformação." As características do trabalho tornam-se fundamentais para a construção da identidade do indivíduo. Dejours (1994) explica que o trabalho não é apenas um teatro aberto ao investimento subjetivo, ele é também um espaço de construção do sentido e, portanto, de conquista da identidade, da comunidade e historicização do sujeito.

\subsection{TRABALHO: PRAZER E SOFRIMENTO}

O prazer e o sofrimento dos indivíduos não podem ser mensurados, pois as percepções e os impactos são diferentes. Nessa dinâmica, Dejours e Abdoucheli (1994, p. 128) relatam que "não conhecemos sofrimento nem prazer de um grupo, de um coletivo, de uma organização ou de uma sociedade. [...] O sofrimento, o prazer, o sujeito, a identidade, são conceitos cujo uso rigoroso não tem validade fora da ordem singular." Quando a qualidade de vida do trabalho deixa de existir, as doenças poderão ser desenvolvidas, seja no ambiente de trabalho seja na vida pessoal. Sobre essa premissa, Dejours e Abdoucheli (1994, p. 125) afirmam que "as pressões ligadas às condições de trabalho têm por alvo principal o corpo dos trabalhadores, onde elas podem ocasionar desgaste, envelhecimento e doenças somáticas.” A seguir, na tabela 2, apresenta-se as aproximações teóricas sobre o prazer e o sofrimento.

Tabela 2 Aproximações teóricas de prazer e sofrimento.

\begin{tabular}{|c|c|c|}
\hline Dimensão & Autores & Pressupostos \\
\hline \multirow{6}{*}{ Prazer } & Chanlat & $\begin{array}{l}\text { O prazer de estudar ou trabalhar em um lugar é também um prazer espacial, um } \\
\text { prazer associado a um espaço onde nos sentimos bem. }\end{array}$ \\
\hline & Gasparini & $\begin{array}{l}\text { A qualidade do trabalho pode também significar a escolha ou, no limite, a } \\
\text { gestão pessoal do tempo de trabalho, quanto a sua duração, sua organização e } \\
\text { seus ritmos. }\end{array}$ \\
\hline & Morin & $\begin{array}{l}\text { O prazer e o sentimento de realização que podem ser obtidos na execução de } \\
\text { tarefas dão um sentido ao trabalho. }\end{array}$ \\
\hline & $\begin{array}{l}\text { Ferreira e } \\
\text { Mendes }\end{array}$ & $\begin{array}{l}\text { O prazer é definido a partir de dois fatores: valorização e reconhecimento no } \\
\text { trabalho. }\end{array}$ \\
\hline & Dejours & $\begin{array}{l}\text { O reconhecimento é o meio pelo qual o sofrimento pode ser transformado em } \\
\text { prazer no trabalho. }\end{array}$ \\
\hline & Mendes & $\begin{array}{l}\text { O reconhecimento é o processo de valorização do esforço e do sofrimento } \\
\text { investido para realização do trabalho, que possibilita ao sujeito a construção de } \\
\text { sua identidade, traduzida afetivamente por vivência de prazer e de realização de } \\
\text { si mesmo. }\end{array}$ \\
\hline \multirow{4}{*}{ Sofrimento } & Dejours & $\begin{array}{l}\text { Quando o rearranjo da organização do trabalho não é mais possível, quando a } \\
\text { relação do trabalhador com a organização do trabalho é bloqueada, o sofrimento } \\
\text { começa. }\end{array}$ \\
\hline & $\begin{array}{l}\text { Dejours e } \\
\text { Abdoucheli }\end{array}$ & $\begin{array}{l}\text { O sofrimento é inevitável e ubíquo. Ele tem raízes na história singular de todo } \\
\text { sujeito, sem exceção. }\end{array}$ \\
\hline & $\begin{array}{l}\text { Ferreira e } \\
\text { Mendes }\end{array}$ & $\begin{array}{l}\text { O sofrimento é definido a partir do fator desgaste, que é a sensação de cansaço, } \\
\text { desânimo e descontentamento com relação ao trabalho. }\end{array}$ \\
\hline & Dejours & $\begin{array}{l}\text { O sofrimento não deve apenas ser considerado uma consequência lamentável ou } \\
\text { infeliz: isso seria uma visão de senso comum. O sofrimento pode também ser }\end{array}$ \\
\hline
\end{tabular}


um ponto de partida e não apenas uma consequência lastimável.

O sofrimento no trabalho surge quando a relação do trabalhador com a organização do trabalho é bloqueada em virtude das dificuldades de negociação

Mendes das diferentes forças que envolvem o desejo da produção e o desejo do trabalhador.

O sofrimento se instala quando a organização do trabalho não permite ao trabalhador uma margem de liberdade/ manobra para efetuar ajustes, rearranjo

Rossi do modo operatório prescrito em conformidade com suas necessidades e desejos.

Adaptado de: Chanlat (1996, p.108-109), Dejours (1994, p. 29), Dejours e Abdoucheli (1994, p. 137), Ferreira e Mendes (2001, p. 96), Gasparini (1996, p. 124), Mendes (2007, p. 36-44), Morin (2001, p. 16), Rossi (2012, p.115).

A valorização e a qualidade de vida no trabalho são fundamentais para a evolução das pessoas. Sob esse fundamento, Limongi-França (2009) exprime que as relações entre trabalho e qualidade de vida representam uma crescente necessidade de valorização das condições de trabalho. Diante das pressões e exigências feitas pelas organizações, ressalta-se que o corpo humano necessita de descanso. Então, Leiter e Maslach (2009) explicam que a carga de trabalho é a área da vida profissional que está mais diretamente associada à exaustão. Exigências excessivas de trabalho provenientes da quantidade de trabalho, da intensidade dos prazos ou da complexidade do trabalho exaurem a energia pessoal.

A compreensão do prazer e do sofrimento é muito relativa ao espaço íntimo, pois dependerá da opinião e da maneira como cada um relaciona com a sua realidade. Nesse encadeamento, conforme Dejours e Abdoucheli (1994, p. 128) relatam que o "prazer e sofrimento são vivencias subjetivas, que implicam um ser de carne e um corpo onde ele se exprime e se experimenta, da mesma forma que a angústia, o desejo, o amor etc.” De acordo com o cotidiano no trabalho e da sua intensidade, isso poderá ocasionar em uma série de malefícios, tanto físicos quanto mentais. Nessa dinâmica, Gatchel e Baum (2009, p. 189) expressam que "contextos do trabalho e a dinâmica social do local de trabalho influenciam a saúde, a doença e a qualidade de vida.”

A busca e o alcance de resultados são necessários para a evolução das organizações. $O$ sofrimento no trabalho faz com que essa realidade se torne distante. Ronchi (2010) afirma que as organizações de um modo geral deveriam se preocupar muito com a saúde dos seus trabalhadores, pois parece paradoxal que queiram aumentar seus resultados e pouco fazem na prática para minimizar o sofrimento no trabalho. Com base no exposto, pode-se entender que uma maneira do sujeito escapar do sofrimento, causado pelo trabalho, é distanciar-se do ambiente organizacional. Assim sendo, Gaulejac (2007, p. 299) enuncia que "para escapar do 
estresse, o indivíduo deve sair do universo da gestão. Caso contrário, ele se prende em um paradoxo, que consiste em procurar a solução do problema naquilo que produz."

O prazer e o sentimento de valorização podem ser constituídos da relação positiva entre as organizações e os indivíduos, através das atividades que os mesmos realizam. Sob esse fundamento Mendes e Tamayo (2001, p. 40) expressam que:

Os valores das organizações podem ser uma das fontes geradoras de prazer no trabalho, desde que favoreçam uma organização do trabalho flexível, marcada pela possibilidade de negociações das regras e normas dos processos de trabalho, com participação dos trabalhadores e gestão coletiva das necessidades individuais e organizacionais.

\section{PROCEDIMENTOS METODOLÓGICOS}

Este trabalho desenvolve-se em torno da percepção dos coordenadores de curso de uma universidade maranhense sobre o sentido do trabalho. Nessa perspectiva, utiliza-se como aspectos metodológicos para o desenvolvimento do trabalho quanto à sua natureza, uma pesquisa básica. Quanto aos objetivos, aplicados os métodos exploratório e descritivo, utilizando-se da abordagem quantitativa para análise dos resultados. A coleta de dados foi realizada por meio da aplicação de questionários em escalonamento likert, com as seguintes opções de resposta: Discordo totalmente $=1$; Discordo parcialmente $=2 ;$ Nem concordo nem discordo $=3$; Concordo parcialmente $=4$ e Concordo totalmente $=5$, onde os dados serão estudados para maior enriquecimento da pesquisa. Os períodos de realização da pesquisa foram os meses de junho e julho de 2015.

Com base nos objetivos, esta pesquisa é classificada como exploratória e descritiva embasada nas teorias acerca do fenômeno estudado, com objetivo de compreender a importância do sentido do trabalho. Quanto à abordagem da pesquisa, esta é quantitativa, pois os dados são analisados pelo levantamento de informações em números e por métodos estatísticos. A partir desse entendimento, percebe-se que, quanto mais informações forem coletadas, mais consistência terão os resultados. Quanto ao universo e amostra da pesquisa, evidências sobre as teorias indicam que a pesquisa é fundamentada e aplicada junto aos coordenadores de curso de uma Universidade privada. Assim sendo, a amostra é composta de todos os coordenadores que puderem ou se dispuseram a responder ao questionário da pesquisa. Como a Universidade possui 35 coordenadores, quanto maior a quantidade de coordenadores pesquisados, melhor será a visão obtida do "sentido do trabalho" na percepção desses gestores. 
Sempre que se desenvolvem pesquisas é importante evidenciar que todas apresentam limitações na sua própria essência; neste artigo, portanto outras informações foram investigadas, mas, contudo, de acordo com o limite do espaço, não foi possível colocar todas. Esta pesquisa é um corte transversal, ou seja; em outro dado momento, diferentes resultados poderão surgir. A amostra foi pequena apesar de ser representativa, com a qual se pode fazer uma série de análises, todavia pode ser um fator limitador. Por se tratar de pesquisa realizada com os coordenadores de apenas uma instituição, embora as características do trabalho do coordenador de curso sejam, teoricamente, muito semelhantes em qualquer Universidade, as realidades das instituições, mesmo de mesma entidade mantenedora (privada, federal, estadual e municipal), poderão ser bastante diferentes, dificultando generalizações. Para a elaboração do questionário, apuração, tratamento e análise dos dados foi utilizado o software Sphinx, versão 5.1, (programa estatístico de pesquisa e análise de dados). Utiliza-se uma média na escala de 1 a 5 , onde o número um representa a menor significância e cinco a maior.

\section{ANÁLISE DOS RESULTADOS}

Para estudar o trabalho e seu sentido, foi aplicado um questionário como método de pesquisa. O questionário foi desenvolvido por um grupo de professores/gestores, tomando por base a fundamentação teórica de Morin (2001), sendo dividido em 8 dimensões principais com diversas afirmativas relacionadas ao trabalho e seu sentido, das quais quatro foram utilizadas neste estudo: "O trabalho é algo que", "Um trabalho tem sentido para mim quando", "As condições de emprego devem apresentar" e "Elementos de definição do trabalho." 25 coordenadores de curso responderam ao questionário proposto, em um ambiente acadêmico, em um universo de 35, correspondendo, portanto, a uma amostra de $71,4 \%$ dos coordenadores em atividade na instituição, o que garante alta representatividade.

Entre os pesquisados predominou o sexo feminino com 56\%. A faixa etária com maior representação compreendeu as idades entre 36 e 45 anos (52\%). As outras duas faixas, consideradas de 26 a 35 e 46 a 55 anos, representam cada, 24\% dos coordenadores indagados. Ao analisar os resultados obtidos nas unidades selecionadas, a seguir, observa-se que os coordenadores possuem uma visão positiva do trabalho e seu sentido.

Tabela 3 Distribuição percentual dos coordenadores pesquisados que concordam com as afirmações sobre "O trabalho é algo que" a média obtida na afirmação em escala de 1 a 5. 


\begin{tabular}{|l|c|c|}
\hline \multicolumn{1}{c|}{$\begin{array}{c}\text { O trabalho é algo que } \\
\text { (Afirmações) }\end{array}$} & $\begin{array}{c}\text { Concordo parcialmente e } \\
\text { Concordo totalmente }\end{array}$ & Média \\
\hline Oferece uma contribuição para a sociedade & $100,00 \%$ & 4,92 \\
\hline Outras pessoas se beneficiam dele & $100,00 \%$ & 4,80 \\
\hline Permite o aperfeiçoamento & $100,00 \%$ & 4,80 \\
\hline Acrescenta valor a alguma coisa & $96,00 \%$ & 4,76 \\
\hline É agradável & $92,00 \%$ & 4,48 \\
\hline Permite um sentido de pertencimento & $88,00 \%$ & 4,36 \\
\hline É mentalmente exigente & $88,00 \%$ & 4,24 \\
\hline Tem um horário predeterminado & $76,00 \%$ & 4,16 \\
\hline Deve-se prestar contas & $76,00 \%$ & 4,04 \\
\hline É central em minha vida & $72,00 \%$ & 4,04 \\
\hline Se faz em um lugar específico & $56,00 \%$ & 3,64 \\
\hline Alguém diz o que se deve fazer & $40,00 \%$ & 3,24 \\
\hline É fisicamente exigente & $40,00 \%$ & 3,32 \\
\hline Que faço pela obrigação & $12,00 \%$ & 2,04 \\
Realizo somente pelo salário & $4,00 \%$ & 2,12 \\
\hline
\end{tabular}

Fonte: Dados da pesquisa (2015).

Analisando-se a tabela 3, percebe-se que o trabalho é algo atribuído às afirmações com maior frequência da dimensão, oferecendo significativa contribuição para a sociedade. Ao considerar as variáveis com maior expressão percentual, colheu-se convergência total entre afirmações como: "Oferece uma contribuição para a sociedade"; "Outras pessoas se beneficiam dele" e "Permite aperfeiçoamento", com um percentual de 100\%. Considerandose uma escala de 1 a 5 em que Concordo parcialmente vale quatro e Concordo totalmente equivale a cinco, obteve-se média de 4,8 para os itens analisados, os quais, comparados com a média global de 4,5, ao considerar as dez afirmações de maior relevância, ficou caracterizada a homogeneidade de tendência das afirmações componentes deste grande grupo "O trabalho é algo que."

Pode-se, portanto, constatar na visão dos coordenadores uma aproximação maior com essas afirmações. Ao serem inqueridos, evidenciaram-se alguns aspectos dissonantes sobre o trabalho, diante das afirmativas "Se faz em um lugar específico", apresentando um percentual de $56 \%$, e $40 \%$ para as variáveis "Alguém diz o que se deve fazer" e "É fisicamente exigente" respectivamente, em comparação ao grupo das afirmações anteriormente analisadas nesta dimensão. Outra variável presente na dimensão estudada, e com bastante relevância, é a afirmativa, "é mentalmente exigente" com frequência de $88 \%$ de concordância. Ao analisar as exigências que o cargo requer, faz-se necessário entender que uma grande parte concordou que o trabalho exige muito mais de suas competências intelectuais do que físicas $(40 \%)$. Ao 


\section{SENTIDO DO TRABALHO: UMA ANÁLISE SOBRE A PERCEPÇÃO DOS COORDENADORES DE CURSOS EM UMA INSTITUIÇÃO UNIVERSITÁRIA \\ DOI: http://dx.doi.org/10.5007/1983-4535.2016v9n3p174}

serem inquiridos acerca da dimensão analisada, existe uma convergência entre as seguintes variáveis: "Tem um horário predeterminado" e "Deve-se prestar contas" com frequência de $76 \%$ respectivamente. Evidencia-se que, na percepção dos investigados, as exigências são importantes para realizarem suas tarefas, demonstrando assim um sentido favorável para o trabalho. A afirmação "É central em minha vida", com $72 \%$ de concordância, caracteriza que o trabalho para os pesquisados é considerado importante para suas vidas.

$\mathrm{Na}$ visão dos investigados, percebeu-se que há uma convergência entre as frequências percentuais resultantes e as afirmativas. O percentual de $12 \%$ de concordância para a afirmação "Que faço pela obrigação", é considerada, nesse contexto, uma questão bastante relevante, pois $88 \%$ dos respondentes não consideram o trabalho como obrigação. Já na afirmativa "Realizo somente pelo salário" o percentual é de $4 \%$ de concordância, significando que $96 \%$ dos pesquisados não trabalham somente pelo salário. Nessa perspectiva constatou-se que os coordenadores de curso possuem uma percepção positiva acerca do trabalho realizado.

\section{Gráfico 1: Um trabalho tem sentido pra mim quando \\ (Concordo parcialmente e Concordo totalmente)}

1. Permite atualizar aprender e evoluir

2. É interessante, dá prazer

3. Faz-me sentir útil e valorizado

4. É feito de maneira eficiente e eficaz/resultados

5. Beneficia aos outros

6. Respeita os meus valores humanos

7. É feito em um ambiente seguro e sadio

8. A carga de trabalho é justa

9. Respeita minha vida pessoal

10. Reconhece minhas competências

11. Permite contato interessante com outros

12. Os objetivos e metas são compartilhados

13. Respeita as minhas convicções pessoais

14. Permite o uso da criatividade e inovação

15. Corresponde aos meus desejos e interesses

16. É feito em um local de justiça e igualdade

17. Eu posso contar com ajuda dos colegas

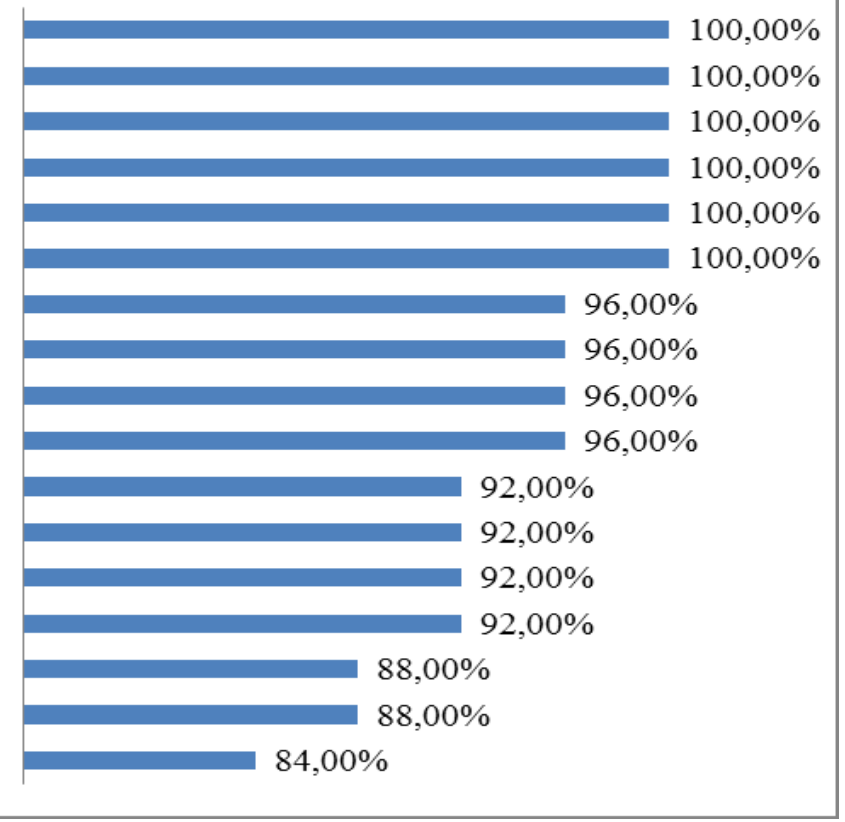

Gráfico 1 Distribuição percentual dos coordenadores pesquisados que concordam com as afirmações sobre "O trabalho tem sentido para mim quando."

Fonte: Dados da pesquisa (2015).

Ao analisar o gráfico 1, a dimensão "Um trabalho tem sentido para mim quando", verificou-se que as variáveis avaliadas obtiveram expressiva frequência percentual. As 
afirmações de 1 a 5, quando observadas, evidenciaram forte convergência entre as concordâncias para as afirmações em 100\%. Percebeu-se que vão ao encontro da teoria estudada, "o prazer e o sentimento de realização que podem ser obtidos na execução de tarefas dão um sentido ao trabalho." (MORIN, 2001, p. 16). Esses dados demonstram que o trabalho é considerado um fator importante para o desenvolvimento profissional e pessoal, na visão dos coordenadores da instituição. Nota-se que as afirmativas possuem respostas favoráveis e positivas quando comparadas à fundamentação teórica.

A afirmação "Respeita os meus valores humanos", com 100\% de concordância, vai ao encontro da teoria de Ronchi (2010, p. 43) expressando que "Através das suas experiências, valores, crenças e pressupostos, cada indivíduo vai criando o significado particular do trabalho.” Ao analisar as afirmações 7; 8; 9 e 10, observou-se, haver convergência entre os resultados em, com $96 \%$ de concordância. Esses dados evidenciam que o trabalho tem sentido para os coordenadores quando existe bem-estar, reconhecimento e respeito. Sob esse fundamento, evidências sobre a teoria indicam que "O prazer de estudar ou trabalhar em um lugar é também um prazer espacial, um prazer associado a um espaço onde nos sentimos bem." (CHANLAT, 1996, p.108-109).

Morin (2001, p. 9) explica que "a organização do trabalho deve oferecer aos trabalhadores a possibilidade de realizar algo que tenha sentido, de praticar e desenvolver suas competências, de exercer seus julgamentos e seu livre-arbítrio, de conhecer a evolução de seus desempenhos e de se ajustar." Sob esse fundamento, quando inqueridos a esse respeito, verificou-se alta convergência entre as afirmativas $11 ; 12 ; 13$ e 14 com proporção de 92\% cada, e as variáveis 15 e 16 com percentuais de $88 \%$, demonstrando claramente coerência entre a teoria estudada e a pesquisa realizada. A afirmação "Eu posso contar com ajuda dos colegas" foi a de menor frequência da dimensão analisada, com $84 \%$ de concordância. Apesar de ser a variável com menor aceitação, em relação às outras afirmações, $84 \%$ é uma proporção bastante forte para caracterizar um sentido também coletivo do trabalho que essa afirmação apresenta.

Tabela 4 Distribuição percentual dos coordenadores pesquisados que concordam com as afirmações sobre "Elementos de definição do trabalho" e média obtida na afirmação em escala de 1 a 5.

\begin{tabular}{|l|c|c|}
\hline \multicolumn{1}{|c|}{$\begin{array}{c}\text { Elementos de definição do trabalho } \\
\text { (Afirmações) }\end{array}$} & $\begin{array}{c}\text { Concordo Parcialmente e } \\
\text { Concordo Totalmente }\end{array}$ & Média \\
\hline $\begin{array}{l}\text { O trabalho que eu faço contribui para a sociedade } \\
\text { Meu trabalho me faz ter um sentimento de vinculação enquanto } \\
\text { realizo }\end{array}$ & $96,00 \%$ & 4,76 \\
\hline
\end{tabular}




\begin{tabular}{|c|c|c|}
\hline Trabalho acrescenta valor a alguma coisa & $96,00 \%$ & 4,60 \\
\hline Trabalho é o que me permite melhorar & $96,00 \%$ & 4,44 \\
\hline Meu trabalho é mentalmente exigente & $92,00 \%$ & 4,60 \\
\hline O trabalho faz parte de minhas tarefas & $84,00 \%$ & 4,16 \\
\hline Trabalho é quando outros se beneficiam & $60,00 \%$ & 3,56 \\
\hline O trabalho é a parte mais importante da minha vida & $60,00 \%$ & 3,72 \\
\hline O trabalho pode ser considerado central as ações do cotidiano & $52,00 \%$ & 3,68 \\
\hline Trabalho é o que faço em um local específico & $40,00 \%$ & 3,32 \\
\hline Trabalho é quando eu faço em um dado momento & $32,00 \%$ & 3,00 \\
\hline O trabalho é fisicamente exigente & $28,00 \%$ & 3,04 \\
\hline Trabalho é quando eu tenho que prestar contas & $24,00 \%$ & 2,68 \\
\hline Trabalho é algo que eu recebo dinheiro para realizar & $20,00 \%$ & 2,28 \\
\hline Trabalhar não é agradável, se pudesse não trabalharia. & $16,00 \%$ & 1,56 \\
\hline Trabalho é quando alguém me diz o que fazer & $12,00 \%$ & 2,52 \\
\hline Trabalho é quando eu sou obrigado a realizar & $4,00 \%$ & 2,08 \\
\hline
\end{tabular}

Fonte: Dados da pesquisa (2015).

Analisando-se os resultados sobre os "Elementos de definição do trabalho" (tabela 4), observou-se coerência entre as variáveis de maior percentual de concordância: "O trabalho que eu faço contribui para a sociedade", "Meu trabalho me faz ter um sentimento de vinculação enquanto realizo", "Trabalho acrescenta valor a alguma coisa", "Trabalho é o que me permite melhorar", com um percentual de 96\%. Ao considerar-se a teoria que fundamenta esta pesquisa, evidenciou-se que os resultados vão ao encontro do que explica Lévy-Leboyer (1994, p. 21-22) quando diz "é o trabalho que de fato situa o indivíduo na sociedade, sendo através das experiências da vida ativa que são construídas a identidade e a personalidade de cada um."

Conforme já apontado na tabela 3, na afirmativa "é mentalmente exigente" com frequência de $88 \%$ de concordância, reforça-se que os percentuais tiveram uma aproximação com a dimensão da tabela 4, na variável "Meu trabalho é mentalmente exigente", com um percentual de 92\%, assim caracterizando bastante relevância entre as afirmativas, e demonstrando que os investigados consideram o trabalho mais exigente psicologicamente do que fisicamente.

Nessa perspectiva, apresentam-se os percentuais que demonstram que o trabalho, na visão dos pesquisados, não é considerado fisicamente exigente. Conforme apontado na tabela 3, na afirmativa "É fisicamente exigente" com uma frequência de 40\%, reforça-se que os percentuais representam uma coerência, aos apresentados na dimensão da tabela 4 (quatro), na afirmação, "O trabalho é fisicamente exigente" com uma frequência de 28\%. Apesar do trabalho dos indivíduos possuírem uma expressão percentual maior, quando se trata que o trabalho exige mais da mente do que fisicamente, isso não quer dizer, necessariamente, que as 
consequências afetem somente o psicológico. Naturalmente o corpo dos trabalhadores sofre também as consequências, ocasionando uma série de perdas, relacionado às inúmeras demandas que o cargo exige. Conforme citado no referencial, reforça-se a teoria de Dejours e Abdoucheli (1994, p. 125), afirmando-se que "as pressões ligadas às condições de trabalho têm por alvo principal o corpo dos trabalhadores, onde elas podem ocasionar desgaste, envelhecimento e doenças somáticas."

As afirmações, "O trabalho faz parte de minhas tarefas", com um percentual de $84, \%$ de concordância, "Trabalho é quando outros se beneficiam", com frequência de $60 \%$, "O trabalho é a parte mais importante da minha vida", apresentando um percentual de $60 \%$ e a variável "O trabalho pode ser considerado central às ações do cotidiano", com $52 \%$, são resultados bastante relevantes, e vão ao encontro com a teoria de Andrade, Tolfo e Dellagnelo (2012, p. 205) expressando que "a centralidade do trabalho consiste no grau de importância atribuída a ele em comparação com as demais esferas da vida." Ao serem confrontados com algumas afirmações evidenciaram-se alguns aspectos relevantes sobre o trabalho, como "Trabalho é quando eu tenho que prestar contas", com $24 \%$, "Trabalho é quando eu faço em um dado momento" 32\%, "Trabalho é o que faço em um local específico", com frequência de $40 \%$. Pode-se, portanto, constatar, na visão dos investigados, uma aproximação maior com essas afirmações, quando se trata da realização do trabalho em um determinado local.

Por se tratar de coordenadores de curso, o trabalho não se realiza somente em um local específico, visto que o mesmo desenvolve diversas atividades relacionadas ao trabalho que realiza. Fica também evidente, para os coordenadores dessa instituição, que o trabalho não é feito só por ter que prestar contas ou que se realize em determinado momento. Esta pesquisa corrobora a teoria de Gaulejac (2007, p. 275) demonstrando que "em toda organização, os indivíduos adaptam seu comportamento aos parâmetros segundo os quais pensam ser julgados."

Ao prosseguir com a análise dos dados desta dimensão, faz-se necessário sinalizar as afirmações, “Trabalhar não é agradável, se pudesse não trabalharia” (16\%), "Trabalho é quando alguém me diz o que fazer" (12\%) e "Trabalho é quando eu sou obrigado a realizar", com 4\% de concordância. Observa-se, portanto, que a grande maioria dos coordenadores pesquisados é contrária a todas elas, caracterizando que o trabalho é agradável, não esperam que o determinem o que fazer e nem trabalham por obrigação. Esses resultados vão ao 


\section{SENTIDO DO TRABALHO: UMA ANÁLISE SOBRE A PERCEPÇÃO DOS COORDENADORES DE CURSOS EM UMA INSTITUIÇÃO UNIVERSITÁRIA \\ DOI: http://dx.doi.org/10.5007/1983-4535.2016v9n3p174}

encontro da teoria de Gaulejac (2007, p. 113) ao afirmar que "o trabalho é apresentado como experiência interessante, enriquecedora e estimulante."

Tabela 5 Distribuição percentual dos coordenadores pesquisados que concordam com as afirmações sobre "As condições de emprego devem apresentar" e média obtida na afirmação em escala de 1 a 5.

\begin{tabular}{l|c|c}
\hline \multicolumn{1}{c|}{$\begin{array}{c}\text { As condições do emprego devem apresentar } \\
\text { (Afirmações) }\end{array}$} & $\begin{array}{c}\text { Concordo Parcialmente e } \\
\text { Concordo Totalmente }\end{array}$ & Média \\
\hline Um salário justo e aceitável. & $100,00 \%$ & 4,84 \\
\hline $\begin{array}{l}\text { Se você tivesse muito dinheiro para viver confortavelmente para } \\
\text { o resto de sua vida, você continuaria a trabalhar? }\end{array}$ & $92,00 \%$ & 4,48 \\
$\begin{array}{l}\text { Preferencialmente um ambiente organizacional agradável, } \\
\text { mesmo com um salário abaixo de média paga para essa função. }\end{array}$ & $60,00 \%$ & 3,88 \\
$\begin{array}{l}\text { Preferencialmente um bom salário, mesmo em um ambiente } \\
\text { organizacional desconfortável. }\end{array}$ & $44,00 \%$ & 2,96 \\
\hline
\end{tabular}

Fonte: Dados da pesquisa (2015)

Ao analisar a dimensão onde se trata sobre o que "As condições de emprego devem apresentar", nota-se que as afirmações contidas são equivalentes, e estão relacionadas ao salário e as condições de emprego. Ao explorar a variável "Um salário justo e aceitável", é notória a sua alta expressão percentual, com 100\% de concordância. Para os investigados o salário é importante e possui bastante significância para que as condições de emprego sejam favoráveis. Comparou-se essa assertiva com tabela 3 (três), na variável "Realizo somente pelo salário" com percentual de 4\% de concordância. Percebe-se que, apesar de declararem que as condições de emprego necessitam de um salário justo e aceitável para que possam trabalhar, os indivíduos confirmam que não trabalham somente pelo dinheiro.

Reforça-se a análise quando comparada com a pergunta, "Se você tivesse muito dinheiro para viver confortavelmente para o resto da vida, você continuaria a trabalhar?", com frequência de $92 \%$ de concordância, assim tornado a averiguação altamente relevante. Ao comparar esta variável com a dimensão da tabela 4 (quatro), na afirmação "Trabalho é algo que eu recebo dinheiro para realizar" com uma expressão percentual de $20 \%$, corrobora-se que os respondentes consideram o trabalho mais importante que o dinheiro, para que possa ser realizado, significando que $80 \%$, não consideram o consideraram um fator principal.

Ao analisar o que "As condições do emprego devem apresentar", constatou-se uma equiparação entre as frequências de menor expressão percentual da dimensão, nas afirmações, "Preferencialmente um ambiente organizacional agradável, mesmo com um salário abaixo de média paga para essa função", com um percentual de $60 \%$ de concordância, e na afirmação 
"Preferencialmente um bom salário, mesmo em um ambiente organizacional desconfortável" com uma expressão percentual de $44 \%$.

Verifica-se que existe uma coerência entre as afirmações, demonstrando que o ambiente organizacional torna-se relevante na percepção dos pesquisados, o que reforça que eles não consideram o dinheiro um fator influente para dar sentido ao trabalho que realizam. Conforme citado no referencial, Ronchi (2010, p. 20) afirma que "as organizações buscam transformar o trabalho em algo positivo para os indivíduos, com a promessa de atender as suas necessidades e garantir a felicidade". Desta maneira as percepções dos coordenadores de curso tornam-se favoráveis para obtenção de resultados satisfatórios, com o objetivo de o trabalho ter sentido.

\section{CONSIDERAÇÕES FINAIS}

A pesquisa possibilitou observar que o trabalho e seu sentido são entendidos pelos coordenadores de curso como um fator positivo para a realização das suas tarefas, sendo satisfatório para quem o realiza, assim contribuindo para a coletividade. Entender como as dimensões do sentido do trabalho influenciam o desempenho dos pesquisados foi fundamental para conseguir um resultado relevante para a Ciência. Para alcançar o objetivo proposto, foi necessário analisar a percepção dos coordenadores de curso, acerca do trabalho que é realizado e de suas variáveis. As análises apresentaram contributos para que o trabalho tenha mais sentido e relevância na vida dos coordenadores de curso.

O sentido do trabalho se dá através de cada indivíduo e da sua visão, pois, não existe uma fórmula pronta para o propósito de cada pessoa; qualquer trabalho fará sentido desde que as pessoas valorizem o que fazem e as organizações reconheçam seu desempenho. Pode-se constatar que os coordenadores de curso possuem uma visão favorável com o trabalho realizado, visando contribuir e agregar valor para a sociedade, e para a organização onde estão inseridos. A compreensão do fenômeno somou de maneira significativa, para o alcance dos resultados e para efetivação da pesquisa. O trabalho é percebido diferentemente por cada um, sendo que existem diversas consequências, tanto boas quanto ruins; o prazer e o sofrimento dos indivíduos podem impactar no seu desempenho e consequentemente nos resultados.

Ao analisar os dados compreende-se que os investigados consideram o trabalho prazeroso e interessante. Além disso, o sentimento de utilidade e o respeito aos valores humanos são altamente relevantes para que o trabalho tenha sentido aos coordenadores de 
curso. No que tange ao sentido do trabalho e seu significado, os resultados da pesquisa foram bastante positivos, denotando a relevância do estudo, onde as maiorias dos respondentes consideram o trabalho que realizam uma condição necessária para desenvolverem suas competências. Quanto às condições de emprego, percebe-se que os pesquisados consideram o salário justo um fator importante para que possam trabalhar, mas não consideram o dinheiro o único fator relevante para exercerem suas atividades.

Verificou-se que algumas variáveis como a evolução, a possibilidade de aprender, contar com a ajuda dos colegas, atualizar-se, garantia de saúde e qualidade de vida, apoiados por um local de justiça e igualdade são considerados também um dos fatores necessários para que o emprego tenha condições suficientes para a execução das tarefas, possibilitando uma perspectiva de evolução de suas carreiras. Corroborou com essa análise, quando inqueridos acerca do dinheiro, pois os respondentes reforçam que existem outros fatores mais importantes que o dinheiro para que seu trabalho tenha sentido.

Nota-se que o trabalho na percepção dos pesquisados é considerado central em suas vidas. Cabe ressaltar que, na visão dos investigados, o sentido do trabalho contribui para a sociedade, beneficiando os outros e permitindo aperfeiçoamento; desta maneira, é evidente a relevância do tema. Considera-se também que o trabalho pode ser definido pela sua alta exigência mental, apesar de existirem prejuízos à saúde física dos indivíduos, ao longo de suas vidas. Com base no que foi discorrido, verifica-se que o sentido do trabalho poderá influenciar o desenvolvimento profissional e pessoal dos coordenadores de curso de uma Universidade, pois as evidências indicam que os pesquisados consideram o trabalho um fator importante para as suas vidas. Conclui-se, então, que o objetivo de diagnosticar o que os coordenadores de curso atribuem ao sentido do trabalho foi atendido, pois, ao serem analisados os dados, compreende-se que os resultados percentuais foram favoráveis e relevantes para compreender o fenômeno em tela.

\section{REFERÊNCIAS}

ANDRADE, S. P. C.; TOLFO, S. R.; DELLAGNELO, E. H. L. Sentidos do trabalho e racionalidades instrumental: interfaces entre a administração e a psicologia. RAC, Rio de janeiro, v. 16, n. 2, p. 200-216, mar./abr. 2012.

AUBERT, N. A neurose profissional. RAE - Revista de Administração de Empresas. São Paulo, v. 33, n. 1, p. 84-105, jan./ fev. 1993.

BAUMAN, Z. Modernidade líquida. Rio de Janeiro: Jorge Zahar, 2001. 
CHANLAT, J. F. O ser humano, um ser espaço-temporal. In: organização: dimensões esquecidas. 3. ed. São Paulo: Atlas, 1996.

O indivíduo na

DEJOURS, C. A carga psíquica do trabalho. In: ; ABDOUCHELI, E.; JAYET, C.

Psicodinâmica do trabalho: contribuições da escola dejouriana à análise da relação prazer, sofrimento e trabalho. São Paulo: Atlas, 1994.

Subjetividade, trabalho e ação. Revista Produção, São Paulo, v. 14, n. 3, p. 27-34, set./dez. 2004.

; ABDOUCHELI, E. Itinerário teórico em psicopatologia do trabalho. In:

; JAYET, C. Psicodinâmica do trabalho: contribuições da escola dejouriana à análise da relação prazer, sofrimento e trabalho. São Paulo: Atlas, 1994.

ENRIQUEZ, E. Vida psíquica e organização. Rio de Janeiro: FGV, 2000.

FERREIRA, M.; MENDES, A. M. Só de pensar em vir trabalhar já fico de mau humor: Atividade de atendimento público e prazer-sofrimento no trabalho. Revista Estudos de Psicologia, Natal, v. 6, n. 3, p. 93-105, 2001.

FREITAS, M. E. Contexto social e imaginário organizacional moderno. RAE - Revista de Administração de Empresas, São Paulo, v. 40, n. 2, p. 6-15, abr./jun. 2000.

GASPARINI, G. Tempo e trabalho no ocidente. In: CHANLAT, J. F. O indivíduo na organização: dimensões esquecidas. 3. ed. São Paulo: Atlas, 1996.

GATCHEL, R. J.; BAUM, A. Mediadores biocomportamentais de stress e qualidade de vida em contextos ocupacionais. In: ROSSI, A. M.; QUICK, J. C.; PERREWÉ, P. L. (Org.). Stress e qualidade de vida no trabalho: o positivo e o negativo. São Paulo: Atlas, 2009.

GAULEJAC, V. Gestão como doença social: ideologia, poder gerencialista e fragmentação social. Aparecida: Ideias \& Letras, 2007.

HALL, S. Quem precisa de identidade?. In: SILVA, T. T.; HALL, S.; WOODWARD, K. Identidade e diferença: a perspectiva dos estudos culturais. 9. ed. Petrópolis,RJ: Vozes, 2009.

LEITER, M. P.; MASLACH, C. Burnout e lesões no local de trabalho: uma análise longitudinal. In: ROSSI, A. M.; QUICK, J. C.; PERREWÉ, P. L. (Org.). Stress e qualidade de vida no trabalho: o positivo e o negativo. São Paulo: Atlas, 2009.

LÉVY-LEBOYER, C. A crise das motivações. São Paulo: Atlas, 1994.

LIMONGI-FRANÇA, A. C. Promoção de saúde e qualidade de vida no trabalho: o desafio da gestão integrada. In: ROSSI, A. M.; QUICK, J. C.; PERREWÉ P. L. (Org.). Stress e qualidade de vida no trabalho: o positivo e o negativo. São Paulo: Atlas, 2009. 
LIPOVETSKY, G. Os tempos hipermodernos. São Paulo: Editora Barcarolla, 2004.

MENDES, A. M. Da psicodinâmica á psicopatologia do trabalho. São Paulo: Casa do Psicólogo, 2007.

. TAMAYO, Á. Valores organizacionais e prazer-sofrimento no trabalho. Psico-USF, Brasília, v. 6, n. 1, p.39-46, jan./jun. 2001.

MORIN, E. M. Os sentidos do trabalho. RAE - Revista de Administração de Empresas, São Paulo, v. 41, n. 3, p. 8-19, jul./set. 2001.

MOTTA, F. C. P. Controle social nas organizações. RAE - Revista de Administração de Empresas, São Paulo, v. 33, n. 5, p. 68-87, set./out. 1993.

RONCHI, C. C. Sentido do trabalho: saúde e qualidade de vida. Curitiba: Juruá, 2010.

ROSSI, E. Z. Método de pesquisa psicodinâmica do trabalho. Curitiba: Juruá, 2012.

TAMAYO, Á. Impacto dos valores pessoais e organizacionais sobre o comprometimento organizacional. In: ; PORTO, J. B. (Org.). Valores e comportamentos nas organizações. Petrópolis, RJ: Vozes, 2005.

TOLFO, S. R. et al. Sentidos y significados del trabajo: un análisis con base en diferentes perspectivas teórico-epistemológicas en Psicología. Univ. Psychol, Bogotá, Colombia, v. 10, n. 1, p. 175-188, ene./abr. 2011.

TOLFO, S. R.; PICCININI, V. Sentidos e significados do trabalho: explorando conceitos, variáveis e estudos empíricos brasileiros. Psicologia \& Sociedade, Porto Alegre, v. 19, $\mathrm{n}^{\circ}$ Especial, 2007. Disponível em: http://www.scielo.br/pdf/psoc/v19nspe/v19nspea07.pdf. Acessado em: 21 abr. 15. 